\title{
Factors Influencing Adjustment in Physical Education and Sports Learning after the COVID-19 Pandemic among Students in the Faculty of Education at Thailand National Sports University
}

\author{
Thitipong Sukdee ${ }^{1, *} \&$ Dittachai Chankuna ${ }^{2}$ \\ ${ }^{1}$ Faculty of Education, Thailand National Sports University, Thailand \\ ${ }^{2}$ Faculty of Liberal Arts, Thailand National Sports University, Thailand \\ *Correspondence: Thailand National Sports University 111 Sukhumvit, Nongmaidaeng, Meung, Chon Buri 20000, \\ Thailand. Tel: 66-89-855-4100. E-mail: peter_book_ja@hotmail.com
}

Received: January 20, 2021

Accepted: February 19, $2021 \quad$ Online Published: April 12, 2021

doi:10.5430/wje.v11n2p24

URL: https://doi.org/10.5430/wje.v11n2p24

\begin{abstract} of descriptive statistics, Pearson correlation, and Stepwise Multiple Regression Analysis. predicted by equations were as follows:

In terms of raw scores:

$\mathrm{Y}^{\prime}=-0.175+0.384\left(\mathrm{X}_{3}\right)+0.265\left(\mathrm{X}_{1}\right)+0.224\left(\mathrm{X}_{4}\right)+0.084\left(\mathrm{X}_{5}\right)+0.064\left(\mathrm{X}_{6}\right)$

In term of standard scores:

$Z_{Y}^{\prime}=0.357\left(Z_{3}\right)+0.356\left(Z_{1}\right)+0.207\left(Z_{4}\right)+0.067\left(Z_{5}\right)+0.062\left(Z_{6}\right)$
\end{abstract}

The purpose of this study is to examine factors influencing the adjustments made to physical education and sports learning among students in the Faculty of Education at Thailand National Sports University after the COVID-19 pandemic. 595 students were selected using stratified random sampling from undergraduates in the Faculty of Education at Thailand National Sports University during Academic Year 2020. The data were then analyzed in terms

The potential influences to the adjustments made to physical education and sports learning after the COVID-19 pandemic among students in Faculty of Education at Thailand National Sports University comprised these 5 variables: 1) activities to promote knowledge of COVID-19 prevention within the university; 2) the university's policies promoting the prevention of COVID-19; 3) facilities within the university; 4) imitating a classmate's adjusted behaviors; and 5) learning in class. These 5 factors could predict the adjustments in physical education and sports learning after the COVID-19 pandemic in the studied group with the percentage of 73.60. The significance

Keywords: adjustment, physical education and sports learning, COVID-19

\section{Introduction}

The spread of COVID-19 has resulted in a global health crisis. Thailand decided to close its schools in an effort to protect public health. This closure also includes activities in Department of Physical Education and Sports Association. This resulted in a pause in the development of sports personnel according to the Sixth National Sports Development Plan (2017-2021), which states that the country is in need of Physical Education teachers for nationwide development in Physical Education and Health Education. The aim of the plan is for children and youth both in and out of the education system to receive quality physical education from teachers whose numbers are sufficient to meet the demand. Children who have received proper physical education should be able to perform basic exercise and play sports properly, be able to watch and play sports when they wish, be aware of the rules, and be instilled with a positive attitude, a sense of discipline, and an awareness of sportsmanship. The plan also includes the establishment of networks in schools and communities. This is to promote collaboration between schools and families in order to encourage exercising and sports as a part of children's lifestyles. This also affects the development of the sports industry, which is an important part in increasing the economic value of sports and the development of relevant knowledge and innovation (Office of the Permanent Secretary of Ministry of Tourism and 
Sports, Thailand, 2017). This agrees with Dunton, Do \& Wang (2020), who stated that short-term changes in PA and SB in reaction to COVID-19 may become permanently entrenched, leading to an increased risk of obesity, diabetes, and cardiovascular disease in children. Programmatic and policy strategies should be geared towards promoting PA and reducing SB over the next 12 months. Also, Oncen \& Tanyeri (2020) found that a significant decrease in the physical activity levels of students attending the Department of Physical Education and Sport Science students was observed during the pandemic caused by the COVID-19 infection. These results should not be ignored, because a significant decrease in physical activity may cause negative effects on blood glucose levels and body composition and increase the risk of depression, among other negative health impacts.

This short but severe stall has also resulted in adjustments to Thailand's education sector. In-class learning has switched to online platforms to which students can log in from their homes. However, learning from home not only affects the effectiveness of class management and adds burden to parents, but it also affects learners' social lifestyles and learning. As these online learning platforms are untested, there are limitations on student assessment and evaluation. Many items in the evaluation list were canceled. More importantly, the effects of COVID-19 pandemic appear to be long-lasing, and they are likely to contribute to the disparity in education, especially for physical education, since it is held outdoors. Learners need to move a great deal and they are quite close to each other, so the very nature of this field means it is nearly impossible to maintain social distancing measures. Therefore, after this pandemic, it will be of great interest to analyze the how the field of Physical Education will need to be modified for future pandemics. (Savagpun, 2020). After the COVID-19 pandemic, the following effects have impacted sports education in Thailand. 1) Disparity in education has long been a major problem in Thailand. Students in some universities do not have personal laptops or high-performance smart phones, internet connections with sufficient speed, or the latest video conferencing software. Their parents might work for low wages. Thus, they are unable to financially support online learning for their children. 2) Online learning is ineffective. Thailand might not be ready to conduct online learning effectively since the systems have never been tested yet, especially in rural areas where the necessary technology is absent. This type of learning might not suit physical education and sports learning, as most activities and practices cannot be conducted online. Moreover, assessment and evaluation are conducted through tests and reports. It is difficult to evaluate sports skills, sports teaching, training, and refereeing in this manner, making these formats unsuitable for measuring students' learning objectives. 3) The effectiveness of physical education and sports teachers is questionable. Only a few teachers have received proper training for remote learning and creating teaching multimedia for online classes. Given the urgent situation, the fact some teachers are unable to use the software will negatively affect the efficiency of teaching. Moreover, as physical education and sports courses consist of theory and practice, problems will occur with practice parts due to not being able to hold suitable activities (Burgess \& Sievertsen, 2020; Kenan Foundation Asia, 2020). This agrees with Varea \& González-Calvo (2020), who analyzed how PE practices have become 'touchless' and bodies are absent using the theoretical concepts of risk and assemblage. Results suggest that pre-service teachers are experiencing a mix of emotions during this time: they miss the physical contact with students and believe the subject of PE is losing its identity as a consequence of the current situation. Additionally, O'Brien (2020) found that physical education teachers are seeking to manage an important tension between the experiential nature of Physical Education as a subject, in light of the institutional and external constraints towards online and blended approaches. This is consistent with Erkan (2019), who found that even when teachers and students have adequate technology to enhance communication/interaction, there is still no guarantee that they would learn successfully. As this study demonstrates, it is equally important to provide facilitatory conditions that encourage the integration of technology tools into learning.

As the first wave of COVID-19 infections began to stabilize, various sectors began discussing the "new normal" which will result in huge adjustments in schools all around the world, and Thailand is no exception. The closing of schools and universities has prompted policymakers, schools, teachers, and students to make an urgent switch to remote learning. This inspires ideas for how remote learning and using technology for learning would become the new normal for Thai education (Pittayapongsakorn, 2020). For reasons explained above, during the restart of learning for the first semester of academic year 2020 in the Faculty of Education at Thailand National Sports University, students will adjust their behaviors in physical education and sports classes appropriately for COVID-19 prevention. Physical education and sports learning will provide additional content on technology and remote learning. This is consistent with Filiz \& Konukman (2020) who studied teaching strategies for physical education during the COVID-19 pandemic and found suitable solutions: 1) Face-to-face education, including strict reduction protocols; 2) Distance education; 3) Hybrid education (at home and school, face-to-face and distance). Also, Lu, Barrett \& Lu (2020) found that physical education instructors will be best served by taking advantage of these extraordinary circumstances and focusing upon the advantages vs. disadvantages of technology and use technology as an 
opportunity to enhance physical education. Furthermore, much of what is effectively taught in the online situation may be further leveraged and utilized in future blended teaching in the post COVID-19 period. Students in Faculty of Education at Thailand National Sports University must strictly follow the university's guideline to prevent the spread of COVID-19. They must take body temperatures, distance themselves from classmates and teachers in Physical Education and Sports classes, use hand sanitizers every time a contact is made with a person or shared equipment, wear masks in lecture classes, drink from their own containers, and willingly provide help if a classmate is having trouble following the anti-COVID-19 guideline.

Adjustment of behaviors in physical education and sports classes is crucial to students' health and achievement. Hence, promoting this adjustment for students in physical education and sports classes is a highly urgent policy for Thailand National Sports University, as it should result in students behaving appropriately in classes after a COVID-19 wave. Previous research by Onthongtim, Laojiranakun, Pojpanitphong \& Duangtib (2017) found that adjustment in behaviors of freshmen in an undergraduate school in Chiang Rai occurred in learning and socializing with friends. The university had also made changes to its environment and student activities. Meanwhile, Niyomtham, Thepmanee \& Thongthai (2017) studied the adjustment in behaviors of students in Rajamangala Institute of Technology, Tak campus. They found that students adapted themselves at high level overall in learning, interactions with teachers, and interactions with friends. Mid-level adjustments were also made to the institute's activities and environment. Learning achievement saw positive correlation with adjustment. Additionally, Chuwijitra, Boonsamai \& Tonput (2018) found that the primary factor affecting cross-cultural adapting among students in international graduate studies in Faculty of Pharmaceutical Sciences, Chulalongkorn University is the education system, followed by factors in social and environmental aspects. Also, Khunaphan, Aneksuk, \& Purananont (2018) found that in private universities, students have the most problems in terms of adapting to their surroundings. Learning problems persist at a medium level. Closson \& Bond (2019) found that social network sites (SNS) including Tumblr, Facebook, and Pinterest were linked to the university's adjustments, while Twitter and Instagram helped students to adjust. The research found that SNS plays essential roles in students' understanding of adjustments they need to make for the university. These can be set as the university's policy. Mettler, Carsley, Joly \& Heath (2019) also found that revealed dispositional mindfulness significantly predicted university adjustment even when controlling for self-efficacy and perceived social support from friends and family. The present study is the first to provide empirical support for the protective role of dispositional mindfulness in university adjustment. Moreover, Yöntem \& Özer (2018) found that the results of the research showed that Rational Emotional Behavioral Therapy Based Adjustment Training contributed to the adjustment of first-year students coming from different cities. The findings of a study by Wider, Mustapha, Halik \& Bahari (2017) showed that peer trust positively influenced academic and social adjustment. Meanwhile, peer communication positively influenced social adjustment, but negatively influenced personal-emotional adjustment. Lastly, peer alienation negatively influenced personal-emotional adjustment, but positively influenced institutional attachment.

The researchers are interested in factors influencing adjustment in physical education and sports learning after the COVID-19 pandemic among students in Faculty of Education at Thailand National Sports University. Factors to be studied consist of 1) factors related to the university's policy that promote the prevention of COVID-19; 2) factors related to the importance of COVID-19 prevention; 3) factors related to activities to promote knowledge of COVID-19 prevention within the university; 4) factors related to facilities within the university; 5) factors related to imitating classmate's adjusted behaviors; 6) factors related to learning in class; and 7) factors related to families. These factors serve as variables in predicting adjustment in physical education and sports learning after the COVID-19 pandemic among students. This can be used as a direction for guidelines in adjustment in physical education and sports learning after the COVID-19 pandemic among students in Faculty of Education at Thailand National Sports University. This research should be able to improve students' efficiency and benefit the management of undergraduate curricula.

\section{Method}

\subsection{Objectives}

1) To study the adjustments made in physical education and sports learning after the COVID-19 pandemic among students in the Faculty of Education at Thailand National Sports University.

2) To create an equation to predict the adjustment in physical education and sports learning after the COVID-19 pandemic among students in Faculty of Education at Thailand National Sports University. 


\subsection{Sample}

The subjects are students in the Faculty of Education at Thailand National Sports University in Academic Years 2020. The sample size needs to be large, according to the rule of thumb suggested by Hair et al. (2018) Kline, (2015) and Schumacker \& Lomax (2016) that Students Faculty of Education at Thailand National Sports University should set the groups to variables ratio at no less than 10:1. This research determined the sample size of 85:1 sample size is 595 students selected as a sample of the study by using a stratified random sampling

\subsection{Variables}

\section{Predict variables}

1) Factors related to the university's policy which promotes the prevention of COVID-19 (X1)

2) Factors related to the importance of COVID-19 prevention (X2)

3) Factors related to activities to promote knowledge of COVID-19 prevention within the university (X3)

4) Factors related to facilities within the university (X4)

5) Factors related to imitating classmate's adjusted behavior (X5)

6) Factors related to learning in class (X6)

7) Factors related to families (X7)

Dependent variables: Adjustments in Physical Education and Sports Learning after the COVID-19 pandemic among students in the Faculty of Education at Thailand National Sports University (Y) consists of four Mode of adaptation (Roy \& Andrew, 1999)

1) Physiologic mode

2) Self-concept mode

3) The role function mode

4) Interdependence mode

\subsection{Research Tools}

The instrument was a questionnaire of factors influencing adjustments in physical education and sports learning after the COVID-19 pandemic among students in Faculty of Education at Thailand National Sports University, with a 1-5 rating scale (Likert, 1932). The research tools were created using the following method:

1) Study relevant information from documents, textbooks, and researches on structure and elements regarding COVID-19 prevention. Used the obtained information to create a questionnaire.

2) Have the entire questionnaire verified and its accuracy evaluated by five experts. Use evaluation persons to determine the questionnaire's The Index of Item-Objective Congruence (IOC). Questions with an IOC of 0.5 and above were used in the questionnaire.

3) Try out the edited version of the questionnaire on 30 students outside the sample group to determine its reliability using Cronbach's alpha coefficient and its discrimination by each item using $27 \%$ high-low groups. The questions with discrimination of 0.2 and above were used in the questionnaire.

Factors influencing adjustment in physical education and sports learning after the COVID-19 pandemic among students in the Faculty of Education at Thailand National Sports University consists of 8 sets with 55 items in total:

1) Factors related to the university's policies that promote the prevention of COVID-19: IOC index of $0.80-1.00$, Cronbach's alpha coefficient of 0.79 , item discrimination of 0.40-0.78

2) Factors related to the importance of COVID-19 prevention: IOC index of 1.00, Cronbach's alpha coefficient of 0.76 , item discrimination of $0.44-0.62$

3) Factors related to activities designed to promote knowledge of COVID-19 prevention within the university: IOC index of $0.80-1.00$, Cronbach's alpha coefficient of 0.78 , item discrimination of 0.51-0.66

4) Factors related to facilities within the university: IOC index of 1.00 , Cronbach's alpha coefficient of 0.77 , item discrimination of $0.36-0.69$

5) Factors related to imitating classmates' adjusted behavior: IOC index of 1.00, Cronbach's alpha coefficient of 0.77 , item discrimination of $0.32-0.69$ 
6) Factors related to learning in class: IOC index of $0.80-1.00$, Cronbach's alpha coefficient of 0.85 , item discrimination of $0.57-0.78$

7) Factors related to families: IOC index of 1.00 , Cronbach's alpha coefficient of 0.77 , item discrimination of 0.30 0.80

8) Adjustment in physical education and sports learning after the COVID-19 pandemic among students in Faculty of Education at Thailand National Sports University: IOC index of $0.80-1.00$, Cronbach's alpha coefficient of 0.91, item discrimination of $0.48-0.81$

\subsection{Data Analysis}

1) Data were analyzed in terms of mean and standard deviation in Factors Influencing Adjustment in Physical Education and Sports Learning after the COVID-19 pandemic among students in Faculty of Education at Thailand National Sports University using Wongrattana's (2017) interpretation criteria as follows.

Mean between $4.50-5.00=$ highest level of suitability

Mean between $3.50-4.49=$ high level of suitability

Mean between $2.50-3.49=$ medium level of suitability

Mean between $1.50-2.49=$ low level of suitability

Mean between $1.00-1.49=$ lowest level of suitability

2) Calculate correlation between 1) factors related to the university's policy which promotes the prevention of COVID-19; 2) factors related to the importance of COVID-19 prevention; 3) factors related to activities to promote knowledge of COVID-19 prevention within the university; 4) factors related to facilities within the university; 5) factors related to imitating classmate's adjusted behaviors; 6) factors related to learning in class, and 7) factors related to families against adjustment in physical education and sports learning after the COVID-19 pandemic among students in the Faculty of Education at Thailand National Sports University using Pearson Product Moment Correlation.

3) Analysis. Analyze factors influencing adjustments in physical education and sports learning after the COVID-19 pandemic among students in the Faculty of Education at Thailand National Sports University using Stepwise Multiple Regression.

\subsection{Hypothesis}

At least one of the following: 1) factors related to the university's policy which promotes the prevention of COVID-19; 2) factors related to the importance of COVID-19 prevention; 3) factors related to activities to promote knowledge of COVID-19 prevention within the university; 4) factors related to facilities within the university; 5) factors related to imitating classmate's adjusted behaviors; 6) factors related to learning in class; and 7) factors related to families is able to predict adjustments in physical education and sports learning after the COVID-19 pandemic among students in Faculty of Education at Thailand National Sports University.

\subsection{Ethical Considerations}

The researcher clearly explained the purpose and the procedures of the study to the participants, including the fact that it was to be used for research, and then obtained informed consent from the participants. This research study was approved by the Human Research Ethics Committee, Thailand National Sports University (certification number: TNSU 162/2563).

Every individual in the sample group was informed of terms and conditions and agreed to participate. The researchers personally explained the details of the research and provided a consent form for participants to sign. Consent was asked of volunteers or their rightful representatives. Aliases were used instead of real names. The names of those involved or caused impact on the sample group were not revealed. All names given were aliases. The research results were presented as conclusions, which were of no influence to those in the sample group.

\section{Results}

1) Factors related to the university's policy that promote the prevention of COVID-19, factors related to the importance of COVID-19 prevention, factors related to activities to promote knowledge of COVID-19 prevention within the university, factors related to facilities within the university, factors related to imitating classmate's adjusted behaviors, factors related to learning in class, factors related to families, and adjustments in physical 
education and sports learning after the COVID-19 were at a high level.

Table 1. Mean, Standard Deviation of Factors Related to the University's Policy Which Promotes the Prevention of COVID-19, Factors Related to the Importance of COVID-19 Prevention, Factors Related to Activities to Promote Knowledge of COVID-19 Prevention within the University, Factors Related to Facilities within the University, Factors related to Imitating Classmate's Adjusted Behaviors, Factors related to Learning in Class, Factors related to Families, and Adjustment in Physical Education and Sports Learning after the COVID-19 Pandemic

\begin{tabular}{|c|c|c|c|}
\hline Factors & $\mathrm{x}$ & $\mathrm{S}$ & level \\
\hline $\begin{array}{l}\text { 1. Factors related to the university's policy which promotes the prevention of } \\
\text { COVID-19 (X1) }\end{array}$ & 4.112 & 0.745 & High \\
\hline 2. Factors related to the importance of COVID-19 prevention (X2) & 4.358 & 0.523 & High \\
\hline $\begin{array}{l}\text { 3. Factors related to activities to promote knowledge of COVID-1 } 9 \text { prevention within } \\
\text { the university (X3) }\end{array}$ & 4.305 & 0.517 & High \\
\hline 4. Factors related to facilities within the university $(\mathrm{X} 4)$ & 4.292 & 0.513 & High \\
\hline 5. Factors related to imitating classmate's adjusted behaviors (X5) & 4.429 & 0.440 & High \\
\hline 6. Factors related to learning in class (X6) & 4.271 & 0.539 & High \\
\hline 7. Factors related to families $(\mathrm{X} 7)$ & 4.161 & 0.777 & High \\
\hline $\begin{array}{l}\text { 8. Adjustment in Physical Education and Sports Learning after the COVID-19 pandemic } \\
\text { (Y) }\end{array}$ & 4.177 & 0.555 & High \\
\hline
\end{tabular}

As shown in Table 1, overall, all factors were at a high level.

2) The result of the correlation of factors influencing adjustment in physical education and sports learning after the COVID-19 pandemic among students in Faculty of Education at Thailand National Sports University in all aspects with statistical significance at the level of .05 .

Table 2. The Correlation of Factors Influencing Adjustments in Physical Education and Sports Learning after the COVID-19 Pandemic among Students in Faculty of Education at Thailand National Sports University

\begin{tabular}{lcc}
\hline \multicolumn{1}{c}{ factors } & $\mathrm{r}$ & $\mathrm{p}$ \\
\hline 1. Factors related to the university's policy which promotes the prevention of COVID-19 & 0.704 & $0.000 *$ \\
(X1) & 0.576 & $0.000 *$ \\
2. Factors related to the importance of COVID-19 prevention (X2) & 0.769 & $0.000 *$ \\
3. Factors related to activities to promote knowledge of COVID-19 prevention within the & 0.716 \\
university (X3) & 0.450 & $0.000 *$ \\
4. Factors related to facilities within the university (X4) & 0.561 & $0.000 *$ \\
5. Factors related to imitating classmate's adjusted behaviors (X5) & 0.573 & $0.000 *$ \\
6. Factors related to learning in class (X6) & $0.000 *$ \\
7. Factors related to families (X7) &
\end{tabular}
$* \mathrm{p}<.05$

As shown in Table 2, the correlation of factors influencing adjustments in physical education and sports learning after the COVID-19 pandemic among students in the Faculty of Education at Thailand National Sports University all aspects with statistical significance at the level of .05 .

3) The result of the analysis of the variance found that there are 5 factors that influence adjustments in physical education and sports learning after the COVID-19 pandemic among students in Faculty of Education at Thailand National Sports University with statistical significance at the level of .05 .

Table 3. Analysis of Variance of Factors Influencing Adjustments in Physical Education and Sports Learning after the COVID-19 Pandemic among Students in the Faculty of Education at Thailand National Sports University

\begin{tabular}{|c|c|c|c|c|c|}
\hline Anova & $\mathrm{SS}$ & df & MS & $\mathrm{F}$ & $\mathrm{p}$ \\
\hline Regression & 135.557 & 5 & 27.111 & 332.669 & $0.000 *$ \\
\hline Residual & 48.001 & 589 & 0.081 & & \\
\hline Total & 183.558 & 594 & & & \\
\hline
\end{tabular}

$* \mathrm{p}<.05$ 
As shown in Table 3, analysis of the variance found that there are 5 factors that influence adjustments in physical education and sports learning after the COVID-19 pandemic among students in the Faculty of Education at Thailand National Sports University with statistical significance at the level of .05

4) The factors that could predict adjustments in physical education and sports learning after the COVID-19 pandemic among students in Faculty of Education at Thailand National Sports University comprised these 5 variables: 1) activities to promote knowledge of COVID-19 prevention within the university; 2) the university's policy which promotes the prevention of COVID-19; 3) facilities within the university; 4) imitating a classmate's adjusted behaviors; and 5) learning in class. These 5 factors could predict the adjustment in physical education and sports learning after the COVID-19 pandemic among students in Faculty of Education at Thailand National Sports University with a percentage of 73.60 .

Table 4. Factors Influencing Adjustment in Physical Education and Sports Learning after the COVID-19 Pandemic among Students in Faculty of Education at Thailand National Sports University

\begin{tabular}{|c|c|c|c|c|c|}
\hline Predictors & $\mathrm{b}$ & Std. Error & $\beta$ & $\mathrm{t}$ & $\mathrm{p}$ \\
\hline Constant & -0.175 & 0.133 & - & -1.311 & 0.190 \\
\hline 1. Factors related to activities to promote & 0.384 & 0.037 & 0.357 & $10.293 *$ & 0.000 \\
\hline \multicolumn{6}{|l|}{$\begin{array}{l}\text { knowledge of COVID-19 prevention within the } \\
\text { university (X3) }\end{array}$} \\
\hline $\begin{array}{l}\text { 2. Factors related to the university's policy that } \\
\text { promote the prevention of COVID-19 (X1) }\end{array}$ & 0.265 & 0.020 & 0.356 & $13.374 *$ & 0.000 \\
\hline $\begin{array}{l}\text { 3. Factors related to facilities within the university } \\
\text { (X4) }\end{array}$ & 0.224 & 0.036 & 0.207 & $6.286^{*}$ & 0.000 \\
\hline $\begin{array}{l}\text { 4. Factors related to imitating classmate's adjusted } \\
\text { behaviors (X5) }\end{array}$ & 0.084 & 0.033 & 0.067 & $2.563^{*}$ & 0.011 \\
\hline 5. Factors related to learning in class (X6) & 0.064 & 0.029 & 0.062 & $2.250^{*}$ & 0.025 \\
\hline Adjusted $\mathrm{R}^{2} 0.736$ & & & & & \\
\hline
\end{tabular}

As shown in Table 4, The factors that could predict adjustments in physical education and sports learning after the COVID-19 pandemic among students in the Faculty of Education at Thailand National Sports University comprised these 5 variables: 1) activities to promote knowledge of COVID-19 prevention within the university; 2) the university's policy which promotes the prevention of COVID-19; 3) facilities within the university; 4) imitating a classmate's adjusted behaviors; and 5) learning in class. The coefficients of the Predictors can be written as follows:

In terms of raw scores:

$\mathrm{Y}^{\prime}=-0.175+0.384\left(\mathrm{X}_{3}\right)+0.265\left(\mathrm{X}_{1}\right)+0.224\left(\mathrm{X}_{4}\right)+0.084\left(\mathrm{X}_{5}\right)+0.064\left(\mathrm{X}_{6}\right)$

Linear regression shows that the constant of adjustments in physical education and sports learning after the COVID-19 pandemic is -0.175 . If participation in activities to promote knowledge of COVID-19 prevention within the university increases by 1 , it is expected that adjustments in physical education and sports learning after the COVID-19 pandemic will increase by 0.384 . If university policies that promote the prevention of COVID-19 increases by 1 , it is expected that adjustments in physical education and sports learning after the COVID-19 pandemic will increase by 0.265 . If facilities within the university increases by 1 , it is expected that adjustments in physical education and sports learning after the COVID-19 pandemic will increase by 0.224 . If imitating a classmate's adjusted behaviors increases by 1 , it is expected that adjustments in physical education and sports learning after the COVID-19 pandemic will increase by 0.084 . Lastly, if learning in class increases by 1 , it is expected that adjustments in physical education and sports learning after the COVID-19 pandemic will increase by 0.064

In term of standard scores:

$\mathrm{Z} / \mathrm{Y}=0.357\left(\mathrm{ZX}_{3}\right)+0.356\left(\mathrm{ZX}_{1}\right)+0.207\left(\mathrm{ZX}_{4}\right)+0.067\left(\mathrm{ZX}_{5}\right)+0.062\left(\mathrm{ZX}_{6}\right)$

Standard linear regression shows that if activities to promote knowledge of COVID-19 prevention within the university increase by 1 standard score, it is expected that adjustments in physical education and sports learning after the COVID-19 pandemic will increase by 0.357 standard score. If university policies that promote the prevention of COVID-19 increase by 1 standard score, it is expected that adjustments in physical education and sports learning 
after the COVID-19 pandemic will increase by 0.356 standard score. If facilities within the university increase by 1 standard score, it is expected that adjustments in physical education and sports learning after the COVID-19 pandemic will increase by 0.207 standard score. If imitating a classmate's adjusted behaviors increases by 1 standard score, it is expected that adjustments in physical education and sports learning after the COVID-19 pandemic will increase by 0.067 standard score. Lastly, if learning in class increases by 1 standard score, it is expected that adjustments in physical education and sports learning after the COVID-19 pandemic will increase by 0.062 standard score.

\section{Discussion and Conclusions}

Based on the results, it is found that there are 5 factors influencing adjustment in physical education and sports learning after the COVID-19 pandemic among students in Faculty of Education at Thailand National Sports University with a significance level of .05. The 5 factors are sorted by effectiveness as follows: 1) activities to promote knowledge of COVID-19 prevention within the university; 2) university policies that promote the prevention of COVID-19; 3) facilities within the university; 4) imitating a classmate's adjusted behaviors; and 5) learning in class. These five factors in combination usable in predicting adjustment in physical education and sports learning after the COVID-19 pandemic with the percentage of 73.60. Thus, the hypothesis has been proven correct. Each of the factors are discussed below.

1) Activities to promote knowledge of COVID-19 prevention is the most important factor in predicting adjustment in physical education and sports learning after the COVID-19 pandemic. The university hold activities to promote basic ideas of how to prevent and contain the spread of COVID-19 via information and social media. The university consistently helps raise awareness of how to prevent the spread of COVID-19. It also receives feedback, concerns, and answers students' questions. Activities promoting public health are frequently held. This agrees with Alves, Samorinha, \& Precioso (2020) who found that students revealed good knowledge about COVID-19. Knowledge and COVID-19 preventive behaviors have positive correlation with statistical significance. Wong et al. (2020) found that culturally and linguistically appropriate health education could be developed to increase the knowledge of South Asians, especially those with lower education levels about COVID-19 and to encourage them to implement the necessary preventive measures. Also, Hatabu et al., (2020) stated that in the logistic and multiple linear regressions, capital regions, high basic knowledge, high information acquisition, correct information explanations contributed positively to preventative action $(\mathrm{p}<0.05)$.

2) University policies that promote the prevention of COVID-19 is the second-highest ranked factors in predicting adjustments in physical education and sports learning after the COVID-19 pandemic as the university set the policy for students to strictly follow anti-COVID-19 guidelines. It has a systematic mechanism in place to prevent the spread of COVID-19. There are practices in preventing the spread of COVID-19, suitable health screening, and allocated budget to contain the spread of COVID-19. This is consistent with Romano (2020), who discovered adapting prevention applications to the intended recipients, especially ethnic and cultural groups. The need to strengthen prevention training in graduate education and strategies to reform the education to meet accreditation and licensing standards are suggested. Additionally, Gilmore et al., (2020) found community engagement structures and the use of community engagement approaches supported contextually specific, acceptable and appropriate COVID-19 prevention and control measures. Beltekin \& Kuyulu (2020) found that measures have been taken to minimize interaction, maintain social isolation, and ensure interpersonal social distance. As a result of these decisions taken by the authorities, educational activities in Turkey were suspended at first. After some time, lessons were given in the form of distance learning on digital platforms.

3) Facilities within the university is the third-highest ranked factor in predicting adjustment in physical education and sports learning after the COVID-19 pandemic as the university possesses sufficient equipment for screening. This equipment is up to date with current standards and instruction manuals are clear and easy to understand. Locations for physical education and sports learning are generally well ventilated and are furnished with emergency equipment. This agrees with Sutiah, Slamet, Shafqat, Supriyono (2020) who stated that schools are required to prepare facilities for integrated learning. To prevent students from contracting COVID-19, remote learning is used, with varying degrees of individual readiness to learn. Blanco \& Eitland (2020) stated that districts and schools will want to prepare their facilities to be safe, healthy places to which students can return. State officials can support districts as they develop plans for closure, cleaning, and reopening of school facilities, both now and in future crises. States should ensure that districts with less capacity to manage operations, less knowledge of strategies to limit infectious disease, or without detailed closure and reopening plans are not disadvantaged at a time when all schools need guidance to ensure the safety of all individuals that come in contact with the school building.

4) Imitating a classmate's adjusted behaviors is the fourth-highest ranked factor in predicting adjustments in physical 
education and sports learning after the COVID-19 pandemic as students give advices and suggestions on health care to fellow students. They also imitate the use of hand sanitizer from their friends, hold conversations, and share knowledge on preventing the spread of COVID-19. Moreover, they follow their friends in purchasing products which help prevent the spread of COVID-19. This is consistent with Markiewicz, Doyle \& Brendgen (2001) who found that Security of attachment to friends in turn predicted best friendship quality. Prosocial behavior in turn predicted both best friendship quality and affective behavior with the friend. Similarly, Srikham, Srisakd \& Phuboonob (2017) studied factors related to social adjustment of the first-year undergraduate students at Mahasarakham University and found that factors that had effect to the social adjustment of the first-year undergraduate students, Mahasarakham University were study expectances, family relationship, friend relationship, lecturer relationships, and self-concept. They had positive relationships with student social adjustment at the significant level .01.

5) Learning in class is the fifth-highest ranked factor in predicting adjustment in physical education and sports learning after the COVID-19 pandemic as learning activities in physical Education and Sports courses follow the COVID-19 prevention guidelines. Teachers occasionally use online platforms to reduce the gathering of students. Social distancing between students is also practiced. Moreover, content from Health Education courses is integrated and self-learning activities are encouraged, thus resulting in student creativity. This agrees with Pllana (2019) who stated that creativity as a first step of the innovation that defines the progress of education especially accelerates the growth of the entire economy within a society. and Octaberlina \& Muslimin (2020) students had to be creative to find solutions and innovations to learning barriers, including maintaining good communication with teachers and understanding best learning styles individually. Similarly, Filiz \& Konukman (2020) stated that the link between student and teacher is important to ensure that learning takes place. The lack of direct interaction in the COVID-19 era has significantly highlighted how valuable. This is a new challenge in teaching physical education, and physical education teachers will be a valuable resource for all students during the COVID-19 pandemic, although there is a debate about how much these values and behaviors can be obtained via distance physical education classes. Physical education teachers' motto should be "Guiding youngsters in the process of becoming physically active and healthy for a lifetime." Uluöz (2020) also found the solution suggestions presented for the elimination of problems in the distance education system as follows, both in our study and other studies in the literature. "Improving distance education infrastructure", "Using web-based additional applications", "Assigning homework instead of exams, being fair in grading", "Exemption and adding additional courses to accelerated programs", "Producing solutions for increasing efficiency in practice classes", "ensuring ease of transportation", etc.

In conclusion, adjustment in physical education and sports learning after the COVID-19 pandemic is of great importance. Students are required to always follow COVID-19 preventive measures in Physical Education and Sports classes to gain the most knowledge in both subjects. Establishing a relationship with one's surroundings through supplies of facilities and interactions with fellow humans through imitation, keeping up with changes in the world through logical intelligence development by holding knowledge expanding activities, and class management as the university's policy will help in understanding such situations and preparing to adapt to such phenomenon's with awareness while living happily.

\section{Recommendations}

Research found that activities to promote knowledge of COVID-19 prevention within the university, university policies that promote the prevention of COVID-19, facilities within the university, imitating a classmate's adjusted behaviors, and learning in class are able to influence the prediction of adjustment in physical education and sports learning after the COVID-19 pandemic. The results of this research have provided correct and proper understanding of factors influencing adjustment in physical education and sports learning after the COVID-19 pandemic among students in the Faculty of Education at Thailand National Sports University. This research can serve as a direction for stakeholders including executives, teachers, and staff in the Faculty of Education at Thailand National Sports University. Those involved with the process can use this study when considering policies on adjustment in physical education and sports learning after the COVID-19 pandemic to promote knowledge and help physical education and sports learning achieve full efficiency. With proper implementation, students can live and study safely and happily. Thus, the development of these factors should be given importance.

\section{References}

Alves, R. F., Samorinha, C., \& Precioso, J. (2020). Knowledge, attitudes and preventive behaviors toward COVID-19: a study among higher education students in Portugal. Journal of Health Research. 
https://doi.org/10.1108/JHR-07-2020-0254

Beltekin, E., \& Kuyulu, I. (2020). The Effect of Coronavirus (COVID19) Outbreak on Education Systems: Evaluation of Distance Learning System in Turkey. Journal of Education and Learning, 9(4), 1-9. https://doi.org/10.5539/jel.v9n4p1

Blanco, M., \& Eitland, E. (2020). Preparing Facilities for Students' Return in the Wake of COVID-19. Retrieved from https://eric.ed.gov/?q $=$ Facilities+the+COVID-19+\&id=ED605574

Burgess, S., \& Sievertsen, H. (2020). Schools, skills, and learning: The impact of COVID-19 on education. Retrieved from https://voxeu.org/article/impact-covid-19-education

Chuwijitra, L., Boonsamai, W., \& Tonput, P. (2018). Factors Affecting Cross-cultural Adaptation of International Graduate Students in the Faculty of Pharmaceutical Sciences, Chulalongkorn University. Mahidol R2R e-Journal, 5(2), 83-94. http://doi.org/10.14456/jmu.2018.1983

Closson, L. M., \& Bond, T. A. (2019). Social Network Site Use and University Adjustment. Educational Psychology, 39(8), 1027-1046. http://dx.doi.org/10.1080/01443410.2019.1618443

Dunton, G. F., Do, B., \& Wang, S. D. (2020). Early effects of the COVID-19 pandemic on physical activity and sedentary behavior in children living in the U.S. BMC Public Health, 20, 1351 https://doi.org/10.1186/s12889-020-09429-3

Erkan, A. (2019). Impact of Using Technology on Teacher-Student Communication/Interaction: Improve Students Learning. World Journal of Education, 9(4), 30-40. https://doi.org/10.5430/wje.v9n4p30

Filiz, B., \& Konukman, F. (2020). Teaching Strategies for Physical Education during the COVID-19 Pandemic. Journal of Physical Education, Recreation \& Dance, 91(9), 48-50. https://doi.org/10.1080/07303084.2020.1816099

Gilmore, B., Ndejjo, R., Tchetchia, A., Claro, V., Mago, E., Diallo, A., Lopes, C., \& Bhattacharyya, S. (2020). Community engagement for COVID-19 prevention and control: a rapid evidence synthesis. BMJ Global Health, 5(10), 1-11. https://doi.org/10.1136/bmjgh-2020-003188

Hair, Jr., J. F., Black, W. C., Babin, B. J., Anderson, R. E., \& Black, R. L. W. C. (2018). Multivariate Data Analysis (8th ed.). Upper Saddle River, NJ: Pearson Prentice Hall.

Hatabu, A., Mao, X., Zhou, Y., Kawashita, N., Wen, Z., Ueda, M., Takagi, T., \& Tian. S. (2020). Knowledge, attitudes, and practices toward COVID-19 among university students in Japan and associated factors: An online cross-sectional survey. PLoS ONE, 15(12), e0244350. https://doi.org/10.1371/journal.pone.0244350

Khunaphan, Aneksuk, \& Purananont. (2018). A Study of Student's Effective Adjustments Process for Living in The Private University. MBU Education Journal, 6(2), 90-103.

Kenan Foundation Asia. (2020). 3 Consequences of COVID-19 on Thai Education. Retrieved from https://www.kenan-asia.org/covid-19-thai-education/

Kline, R. B. (2015). Principles and practice of structural equation modeling (4th ed.). New York, NY, US: Guilford Press.

Likert, R. (1932). A technique for the measurement of attitudes. Archives of Psychology, 140, 1-55.

Lu, C., Barrett, J., \& Lu, O. (2020). Teaching Physical Education Teacher Education (PETE) Online: Challenges and Solutions. Journal of educational research and practice, 29(2), 13-17.

Markiewicz, D., Doyle, A., \& Brendgen, M. (2001). The quality of adolescents' friendships: Associations with mothers' interpersonal relationships, attachments to parents and friends, and prosocial behaviors. Journal of Adolescence, 24(4), 429-445. https://doi.org/10.1006/jado.2001.0374

Mettler, J., Carsley, D., Joly, M., \& Heath, N. L. (2019). Dispositional Mindfulness and Adjustment to University. Journal of College Student Retention: Research, Theory \& Practice, 21(1), 38-52. http://dx.doi.org/10.1177/1521025116688905

Niyomtham, O., Thepmanee, M., \& Thongthai, V. (2017). Adjustment of students in Rajamangala University technology Lannatak. Journal of Educational Research Faculty of Education, Srinakharinwirot University, 12(1), 273-285.

O’Brien, W., Adamakis, M., O’ Brien, N., Onofre, M., Martins, J., Dania, A., Makopoulou, K., Herold, F., Ng, K., \& 
Costa, J. (2020). Implications for European Physical Education Teacher Education during the COVID-19 pandemic:a cross-institutional SWOT analysis. European Journal of Teacher Education, 43(4), 503-522. http://dx.doi.org/10.1080/02619768.2020.1823963

Octaberlina, L. R., \& Muslimin, A. L. (2020). EFL Students Perspective towards Online Learning Barriers and Alternatives Using Moodle/Google Classroom during COVID-19 Pandemic. International Journal of Higher Education, 9(6), 1-9. https://doi.org/10.5430/ijhe.v9n6p1

Office of the Permanent Secretary of Ministry of Tourism and Sports, Thailand. (2017). The 6th National Sport Development Plan (2017-2021). Bangkok: Office of the War Veterans Organization Printing House.

Oncen, S., \& Tanyeri, L. (2020). Evaluation of the Physical Activity Levels of the Students in a Physical Education and Sports Science Department before and during the Coronavirus Pandemic. International Education Studies, 13(10), 148-156. https://doi.org/10.5539/ies.v13n10p148

Onthongtim, S., Laojiranakun, L., Pojpanitphong, S., \& Duangtib, C. (2017). Adjustment of first-year undergraduate students at higher education institutions within Muang district. Chiang Rai Province. APHEIT Humanities and Social Sciences Journal, 23(1), 18-25.

Pittayapongsakorn, N. (2020). What is TDRI New Normal of Thai education when learning distance is not the answer. Retrieved from https://tdri.or.th/ 2020/05/ desirable-new-normal-for-thailand-education

Pllana, D. (2019). Creativity in Modern Education. World Journal of Education, 9(2), 136-140. https://doi.org/10.5430/wje.v9n2p136

Romano, J. L. (2020). Politics of Prevention: Reflections from the COVID-19 Pandemic. Journal of Prevention and Health Promotion, 1(1), 34-57. https://doi.org/10.1177/2632077020938360

Roy, C., \& Andrew, H. A. (1999). The Roy Adaptation Model (2nd ed.). Connecticut: Appleton \& Lange.

Savagpun, P. (2020). A new normal of a physical education classroom model with the COVID-19 revolution. Journal of Education Naresuan University, 22(3), 351-357.

Schumacker, R., \& Lomax, R. (2016). A Beginner's Guide to Structural Equation Modeling (4th ed.). New York: Routledge.

Srikham, O., Srisakd, O., \& Phuboonob, J. (2017). The Factors Related to Social Adjustment of the First Year undergraduate Students at Mahasarakham University. Journal of Educational Measurement Mahasarakham University, 23(Special issue), 292-301.

Sutiah, S., Slamet, S., Shafqat, A., \& Supriyono, S., (2020). Implementation of distance learning during the COVID19 in Faculty of Education and Teacher Training. Cypriot. Journal of Educational Science, 15(5), 1204-1214. https://doi.org/10.18844/cjes.v15i5.5151

Uluöz, E. (2020). Opinions of the Faculty of Sport Sciences Students on the Changes in Education System during COVID-19 Pandemic: A Qualitative Research. African Educational Research Journal, 8(3), 481-490. https://doi.org/10.30918/AERJ.83.20.114

Varea, V., \& González-Calvo, G. (2020). Touchless classes and absent bodies: teaching physical education in times of Covid-19. Sport, Education and Society. https://doi.org/10.1080/13573322.2020.1791814

Wider, W., Mustapha, M., Halik, M., \& Bahari, F. (2017). Attachment as a Predictor of University Adjustment among freshmen: Evidence from a Malaysian Public University. Malaysian Journal of Learning and Instruction, 14(1), 111-144.

Wong, C. L., Chen, J., Chow, K. M., Law, B. M. H., Chan, D. N. S., So, W. K. W., Leung, A. W. Y., \& Chan, C. W. H. (2020). Knowledge, Attitudes and Practices towards COVID-19 amongst Ethnic Minorities in Hong Kong. International Journal of Environmental Research and Public Health, 17(21), 7878. https://doi.org/10.3390/ijerph17217878

Wongrattana, C. (2017). Statistical techniques for research (13th ed.). Bangkok: Amon Printing.

Yöntem, M. K., \& Özer, Ö. (2018). The Effect of Adjustment Training Based on Rational Emotive Behavior Therapy on Adjustment to University. International Journal of Higher Education, 7(4), 90-98. https://doi.org/10.5430/ijhe.v7n4p90 


\section{Copyrights}

Copyright for this article is retained by the author(s), with first publication rights granted to the journal.

This is an open-access article distributed under the terms and conditions of the Creative Commons Attribution license (http://creativecommons.org/licenses/by/4.0/). 